\title{
Dielectric response and pyroelectric properties of lead-free ferroelectric $\mathrm{Ba}_{3}\left(\mathrm{VO}_{4}\right)_{2}$
}

\author{
Biswajit Pati* $^{*}$, R. N. P. Choudhary ${ }^{\dagger}$, Piyush R. Das ${ }^{\star}$ and B. C. Sutar $\$$ \\ *Department of Physics, J.K.B.K. Government College, Cuttack 753004, India \\ ${ }^{\dagger}$ Department of Physics, Institute of Technical Education and Research \\ Siksha O Anusandhan University, Bhubaneswar 751030, India \\ ${ }^{*}$ Department of Physics, Veer Surendra Sai University of Technology \\ Burla, Sambalpur 768018, India \\ $\S_{\text {Department of Physics, Hi-Tech College Engineering }}$ \\ Bhubaneswar 751025, India \\ "bpati_ctc@rediffmail.com
}

Received 31 December 2014; Revised 8 February 2015; Accepted 12 February 2015; Published 23 March 2015

\begin{abstract}
The current paper presents results of dielectric response, pyroelectric behavior and conductivity study of lead-free ferroelectric barium orthovanadate $\left(\mathrm{Ba}_{3}\left(\mathrm{VO}_{4}\right)_{2}\right.$ or $\left.\mathrm{Ba}_{3} \mathrm{~V}_{2} \mathrm{O}_{8}\right)$ ceramic, for a wide range of temperature and frequency. An X-ray diffraction study suggests the formation of a single-phase compound in trigonal crystal system. The SEM micrograph of gold-coated pellet sample shows well-defined and homogeneous morphology. Detailed studies of dielectric parameters $\left(\varepsilon_{r}\right.$ and $\left.\tan \delta\right)$ of the compound as a function of temperature and frequency reveal their independence over a wide range of temperature and frequency. The nature of Polarization versus electric field $(P-E)$ hysteresis loop of $\mathrm{Ba}_{3} \mathrm{~V}_{2} \mathrm{O}_{8}$ at room temperature suggests its ferroelectric nature. The temperature dependence of pyroelectric coefficient and figure of merits of the sample support its dielectric response. The nature of variation of dc conductivity with temperature confirms the Arrhenius and negative temperature coefficient of resistance (NTCR) behavior of the material.

Keywords: X-ray diffraction; Palmierite structure; dielectric properties; pyroelectric properties.
\end{abstract}

\section{Introduction}

The discovery of unusual nonlinear switching properties in Rochelle salt by Valasek ${ }^{1}$ in 1921 , and later on the extensive investigation on the same in barium titanate $\left(\mathrm{BaTiO}_{3}\right)$ of perovskite family, ${ }^{2,3}$ has drawn much attention of researchers to investigate new promising materials of different structural families useful for devices. In the quest of searching for new materials, a number of simple and complex oxides, derived from perovskite structure, are extensively studied for their greater structural stability required for devices. ${ }^{4,5}$ Among the large number complex oxides studied so far, some lead-based perovskites such as $\mathrm{Pb}(\mathrm{MgNb}) \mathrm{O}_{3}(\mathrm{PMN}), \mathrm{Pb}\left(\mathrm{Zn}_{1 / 3} \mathrm{Nb}_{2 / 3}\right) \mathrm{O}_{3}$ $(\mathrm{PZN}), \mathrm{Pb}(\mathrm{ZrTi}) \mathrm{O}_{3}$ (PZT), etc., were extensively studied because of their excellent dielectric, ferroelectric and pyroelectric properties useful for an array of applications starting from multilayer capacitors, sensors, to actuators ${ }^{6-10}$ and many more. However, these lead-based compounds exhibit compositional fluctuations due to evaporation of $\mathrm{PbO}$, if incorrectly fabricated. This $\mathrm{Pb}$-evaporation may lead to environmental pollution and at the same time may affect the mechanical and electrical properties of these materials. Therefore, to answer the materials' limitations attempts were made to replace these lead-based compounds with some suitable nonlead counterparts. ${ }^{11-13}$ In the process of searching new nontoxic oxides, orthovanadates of alkaline earth metals with a general formula of $\mathrm{M}_{3}\left(\mathrm{VO}_{4}\right)_{2}(\mathrm{M}=$ divalent metal), have attracted much attention of the scientists for their structural stability, promising ferroelectric properties and low loss for microwave applications. ${ }^{14,15}$ Though $\mathrm{V}_{2} \mathrm{O}_{5}$ is also toxic in nature, yet at times some balanced compromises are to be made for tailoring of potential candidates suitable for devices. This cation-deficient perovskite-based material with a general formula $\mathrm{M}_{n} \mathrm{~V}_{n-\delta} \mathrm{O}_{3 n-x}(\delta \geq 1, x \geq 0)$ is prepared by varying the ratio of cubic (c) and hexagonal (h) stacking of $\left(\mathrm{MO}_{3}\right)$ layers. With $n=3, \delta=1$, and $x=1$, one of every three $\mathrm{V}^{5+}$-sites to remain unoccupied ${ }^{16,17}$ and at the same time, the formation of oxygen-deficient cubic $\left(\mathrm{MO}_{2}\right)$ layers force a change in coordination of the $\mathrm{V}$-atoms from octahedral to tetrahedral. As a result, barium orthovanadate $\left(\mathrm{Ba}_{3} \mathrm{~V}_{2} \mathrm{O}_{8}\right)$ is expected to have palmierite structure. ${ }^{15}$ The presence of oxygen vacancy and the notorious behavior of $\mathrm{V}^{5+}$ ions account for its high-temperature ferroelectric nature $^{15}$ and high-electronic conductivity. ${ }^{18,19}$ The study further suggests that the compound gets decomposed at ambient atmosphere and temperature because of their compositional fluctuation with experimental conditions.

This is an Open Access article published by World Scientific Publishing Company. It is distributed under the terms of the Creative Commons Attribution 3.0 (CC-BY) License. Further distribution of this work is permitted, provided the original work is properly cited. 
Detailed literature survey reveals that such metal orthovanadates have found many potential applications such as in fabrication of luminescent lamp coatings, television tubes, flat panel displays, microwave filters and antennas, etc. ${ }^{18-24}$ Umemura et al. ${ }^{20}$ reported the excellent microwave dielectric properties of the divalent barium and strontium orthovanadate. As reported in Grzechnik et al. ${ }^{21}$ such orthovanadates show intense rare-earth activated luminescence. The laser action of $\mathrm{Mn}^{5+}$-doped $\mathrm{Ba}_{3} \mathrm{~V}_{2} \mathrm{O}_{8}$ has also been reported by Merkle et al. $^{22}$ and Buijsse et $a l^{23}$ In addition, some studies on the structural and impedance properties of this compound have been reported. ${ }^{24,25}$ Recently, several researchers have reported the structural and electrical properties of some of the orthovanadates $^{26,28}$ of this family.

Some of the interesting findings from the previous experimental analysis of the compounds reveal that each member of the family behaves differently even though they look similar. Therefore, it is required to study the details of each member for possible device applications. In view of this, we have studied many compounds of the reported family, and have reported their characteristics. The present work is an attempt to synthesize lead-free complex perovskite, $\mathrm{Ba}_{3} \mathrm{~V}_{2} \mathrm{O}_{8}$, by a standard solid-state reaction route and to study its dielectric, pyroelectric properties and conduction mechanism for better understanding of the material.

\section{Experimental Procedure}

Polycrystalline ceramic samples of $\mathrm{Ba}_{3} \mathrm{~V}_{2} \mathrm{O}_{8}$ were prepared from analytical reagent (AR) grade chemicals; $\mathrm{BaCO}_{3}\left(99.9 \%, \mathrm{M} / \mathrm{s}\right.$ Finar Chem. Pvt. Ltd., India) and $\mathrm{V}_{2} \mathrm{O}_{5}$ (99.9\%, M/s LOBA Chemie Pvt. Ltd., India) using a hightemperature solid-state synthesis route according to the chemical reaction:

$$
3\left(\mathrm{BaCO}_{3}\right)+\mathrm{V}_{2} \mathrm{O}_{5} \rightarrow \mathrm{Ba}_{3}\left(\mathrm{VO}_{4}\right)_{2}+3\left(\mathrm{CO}_{2}\right) \uparrow
$$

at $950^{\circ} \mathrm{C}$ for $4 \mathrm{~h}$ under controlled heating and cooling cycles. The completion of reaction and formation of the desired compound were checked from the X-ray diffraction (XRD) spectra of the material, recorded at room temperature using a X-ray powder diffractometer (X'PERT-PRO, PANalytical) using $\mathrm{CuK}_{\alpha}$ radiation $(\lambda=1.5405 \AA)$ over a wide range of Bragg angle $\theta\left(0^{\circ} \leq 2 \theta \leq 60^{\circ}\right)$ with a scanning speed of $2^{\circ}$ min. The calcined powder was cold pressed into circular discshaped pellets $(\sim 10 \mathrm{~mm}$ diameter and $\sim 1-2 \mathrm{~mm}$ thickness $)$ using polyvinyl alcohol as the binder and applying an isostatic pressure of $4 \times 10^{6} \mathrm{~N} / \mathrm{m}^{2}$. The disc-shaped pellets were subsequently sintered at $980^{\circ}$ under air atmosphere for $4 \mathrm{~h}$ and cooled down to room temperature by furnace cooling. Since the evaporation of $\mathrm{V}_{2} \mathrm{O}_{5}$ at high temperature is very strong, some necessary precautions were taken to control the loss of $\mathrm{V}_{2} \mathrm{O}_{5}$ in this orthovanadate compound. An additional $1 \%$ of $\mathrm{V}_{2} \mathrm{O}_{5}$ by weight was added while weighing the precursors in proper stoichiometry was measured. Secondly, both calcination and sintering were carried out in covered crucible to avoid/minimize evaporation of $\mathrm{V}_{2} \mathrm{O}_{5}$. For electrical measurements, the sintered disc-shaped pellet was polished and then electroded with air-drying conducting silver paste. The silver-coated pellet was then dried at $150^{\circ} \mathrm{C}$ for $8 \mathrm{~h}$ to remove moisture (if any). The dielectric and other related parameters were measured as a function of temperature $\left(30-500^{\circ} \mathrm{C}\right)$ and frequency $(1 \mathrm{kHz}-1 \mathrm{MHz})$ using a computercontrolled phase sensitive meter (PSM LCR 4NL, Model: 1735, UK), a laboratory-designed sample holder and a small vertical pit furnace. An input signal of constant voltage amplitude $\sim 1 \mathrm{~V}$ was applied across the sample for the measurement. The polarization (hysteresis loop) of the poled sample (electric field $=10 \mathrm{kV} / \mathrm{cm}$, time $=8 \mathrm{~h}$ ) was obtained at different temperatures using a workstation of hysteresis loop tracer (M/S Marine India, New Delhi). The pyroelectric current of the pellet sample was measured at different temperatures $\left(30-480^{\circ} \mathrm{C}\right)$ by an electrometer (Keithley Instruments Inc., Model 6517B) at the heating rate of nearly $2^{\circ} \mathrm{C} /$ min. A constant voltage was applied across the sample to measure the dc conductivity using the same electrometer.

\section{Results and Discussion}

\subsection{Structural properties}

Figure 1 shows XRD pattern of $\mathrm{Ba}_{3} \mathrm{~V}_{2} \mathrm{O}_{8}$ calcined powder taken at room temperature. The diffraction pattern shows a number of sharp peaks that are different from those of the ingredients. The well-resolved sharp peaks in the XRD pattern indicate better homogeneity and crystallization of the material without any significant trace of pyrochlore and any other phase. All the observed diffraction peaks of the XRD profile were indexed and the refined lattice cell parameters were determined using the least-squares sub-routine of the standard computer program package "POWD". ${ }^{29}$ The good agreement between the observed and calculated interplanar spacing $\left(d\right.$-values) (i.e., $\sum \Delta d=d_{\text {obs }}-d_{\text {cal }}=$ minimum)

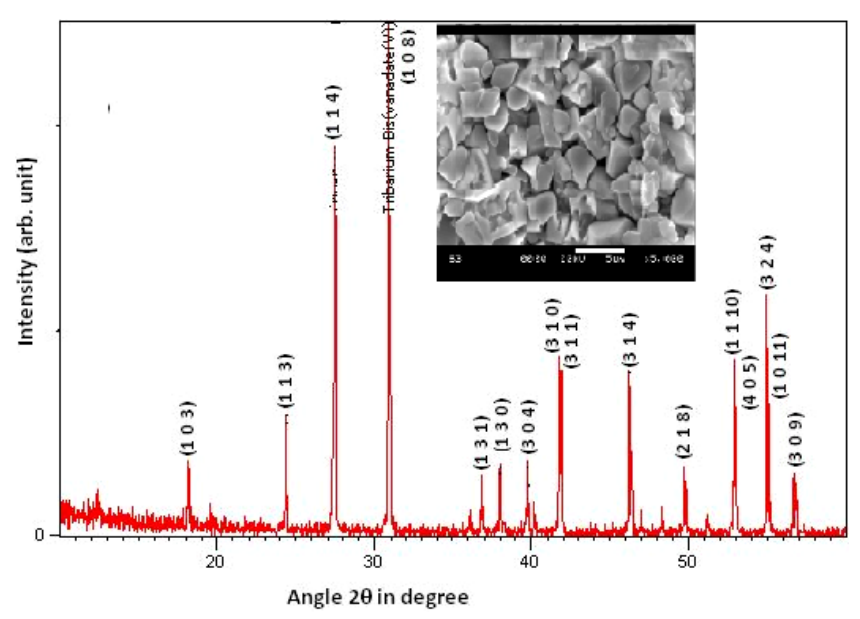

Fig. 1. XRD pattern and SEM of $\mathrm{Ba}_{3} \mathrm{~V}_{2} \mathrm{O}_{8}$ at room temperature. 
Table 1. Comparison of $d_{\mathrm{obs}}, d_{\mathrm{cal}}$ and Miller indices of XRD peaks.

\begin{tabular}{|c|c|c|c|c|c|c|}
\hline \multirow[b]{2}{*}{ S. No. } & \multirow[b]{2}{*}{$2 \theta\left({ }^{\circ}\right)$} & \multicolumn{3}{|c|}{ Miller indices } & \multicolumn{2}{|c|}{$d$-spacing } \\
\hline & & $h$ & $k$ & $l$ & $d_{\text {dobs }}$ & $d_{\mathrm{dcal}}$ \\
\hline 1 & 18.17 & 1 & 0 & 3 & 4.8781 & 4.8723 \\
\hline 2 & 24.35 & 1 & 1 & 3 & 3.6508 & 3.6478 \\
\hline 3 & 27.45 & 1 & 1 & 4 & 3.2464 & 3.2432 \\
\hline 4 & 30.89 & 1 & 0 & 8 & 2.8923 & 2.8993 \\
\hline 5 & 39.75 & 3 & 0 & 4 & 2.2657 & 2.2695 \\
\hline 6 & 41.80 & 3 & 1 & 0 & 2.1592 & 2.1583 \\
\hline 7 & 41.93 & 3 & 1 & 1 & 2.1528 & 2.1546 \\
\hline 8 & 46.22 & 3 & 1 & 4 & 1.9624 & 1.9604 \\
\hline 9 & 49.69 & 2 & 1 & 8 & 1.8332 & 1.8327 \\
\hline 10 & 52.87 & 1 & 1 & 10 & 1.7302 & 1.7300 \\
\hline 11 & 53.02 & 4 & 0 & 5 & 1.7257 & 1.7268 \\
\hline 12 & 54.96 & 3 & 2 & 4 & 1.6692 & 1.6683 \\
\hline 13 & 55.11 & 1 & 0 & 11 & 1.6651 & 1.6647 \\
\hline 14 & 56.64 & 3 & 0 & 9 & 1.6239 & 1.6241 \\
\hline
\end{tabular}

(Table 1) suggests that the compound has trigonal structure at room temperature with refined lattice parameters: $a=8.9859(3) \AA$ and $c=18.7456(3) \AA$, where the number in the parenthesis denotes the standard deviation which is of the order of $10^{-4} \AA$. The refined unit cell parameters with proposed crystal structure (trigonal) are in good agreement with the crystallographic data of $\mathrm{Ba}_{3} \mathrm{~V}_{2} \mathrm{O}_{8}$ (JCPDS: 71-2060) and also with the earlier reported works on the said compound. ${ }^{15,25,30}$ XRD study also suggests that the specimen is of single phase.

Figure 1 (inset) shows the SEM micrograph of the sintered pellets recorded at room temperature. The micrograph shows a well-defined and homogeneous morphology for the sample. In spite of sintering at optimized high temperature, some voids of irregular shape and dimension are still observed. The calculated value of the density of the final sintered pellets was $4.32 \times 10^{3} \mathrm{~kg} / \mathrm{m}^{3}$, which is about $88 \%$ of the theoretical value of density $\left(4.88 \times 10^{3} \mathrm{~kg} / \mathrm{m}^{3}\right)$ of the material. Most of the grains have dimension in the range of $\sim 2-6 \mu \mathrm{m}$.

\subsection{Dielectric properties}

The basic electrical study on the material reveals that its dielectric parameters depend not only on their geometry and temperature, but also on the frequency of applied electric field. Figure 2(a) shows the temperature dependence of dielectric constant $\left(\varepsilon_{r}\right)$ of $\mathrm{Ba}_{3} \mathrm{~V}_{2} \mathrm{O}_{8}$ at two selected frequencies $(10 \mathrm{kHz}$ and $1 \mathrm{MHz})$. The decrease in $\varepsilon_{r}$ with increasing frequency is a general feature of dielectric materials. ${ }^{31,32}$ For a given frequency, the value of $\varepsilon_{r}$ is almost constant over the low and medium temperature ranges (from room temperature to about $300^{\circ} \mathrm{C}$ ) and increases gradually thereafter with further rise in temperature. The nature of dielectric response is similar to the one reported in our earlier work on the said compound. ${ }^{25}$ At higher temperatures, the increase of

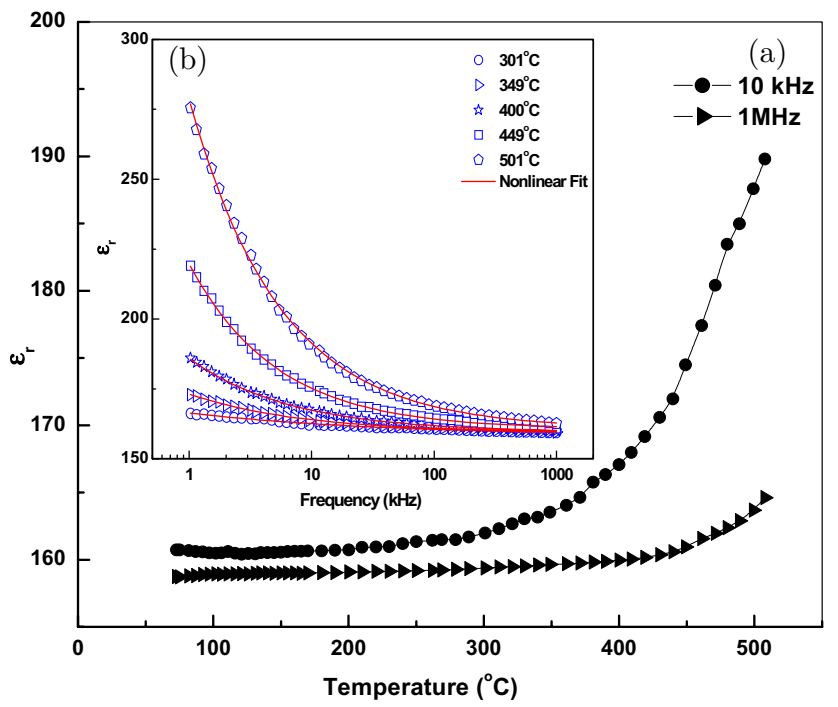

Fig. 2. (a) Temperature dependence of $\varepsilon_{r}$ of $\mathrm{Ba}_{3} \mathrm{~V}_{2} \mathrm{O}_{8}$ at various frequencies and (b) frequency dependence of $\varepsilon_{r}$ of $\mathrm{Ba}_{3} \mathrm{~V}_{2} \mathrm{O}_{8}$ at various temperatures along with nonlinear fit.

$\varepsilon_{r}$ (at lower frequencies) may be attributed to space charge polarization which arises from mobility of ions and imperfections in the material. ${ }^{24,33}$ Further, the presence of $\mathrm{V}^{4+}$ ions accounts for its high temperature ferroelectrics. ${ }^{34}$

Figure 2(b) shows the variation of dielectric constant of the sample with frequency at some selected temperatures. The graph shows a sharp decrease in the value of $\varepsilon_{r}$ in low-frequency region whereas the fall is relatively slow at higher frequencies. This typical behavior of the dielectric sample can be suitably answered with the help of Maxwell-Wagner theory and Koop's phenomenological model. ${ }^{35}$ As per this model, a dielectric medium is considered to be made up of highly conducting grains and poorly conducting grain boundaries. The grain boundaries are more effective at lower frequencies while the grains at higher frequencies. In metal orthovanadates, electrons being the majority charge carriers, the hopping of electrons take place between $\mathrm{V}^{5+}$ ions and $\mathrm{V}^{4+}$ ions present at crystallographically equivalent sites. The small value of $\varepsilon_{r}$ at higher frequencies may be due to the fact that the electron hopping between $\mathrm{V}^{5+}$ and $\mathrm{V}^{4+}$ ions at octahedral sites cannot follow the alteration of ac electric field at higher frequencies. Therefore, electrons have to pass through the well-conducting grains and the poorly conducting grain boundaries. Since grain boundaries offer high resistance, the electrons get crowded there and thus producing an enhanced space charge polarization. As a result, $\varepsilon_{r}$ has larger values in the low-frequency range. With increasing frequency, the direction of motion of electrons changes rapidly. This hinders the movement of electrons inside the dielectric materials and thereby reducing accumulation of charges at grain boundaries. This results in a decrease in space charge polarization and so also the values of relative permittivity. ${ }^{36}$

The continuous line in the frequency-dependent dielectric constant plot is the theoretical fitting of experimental data by 


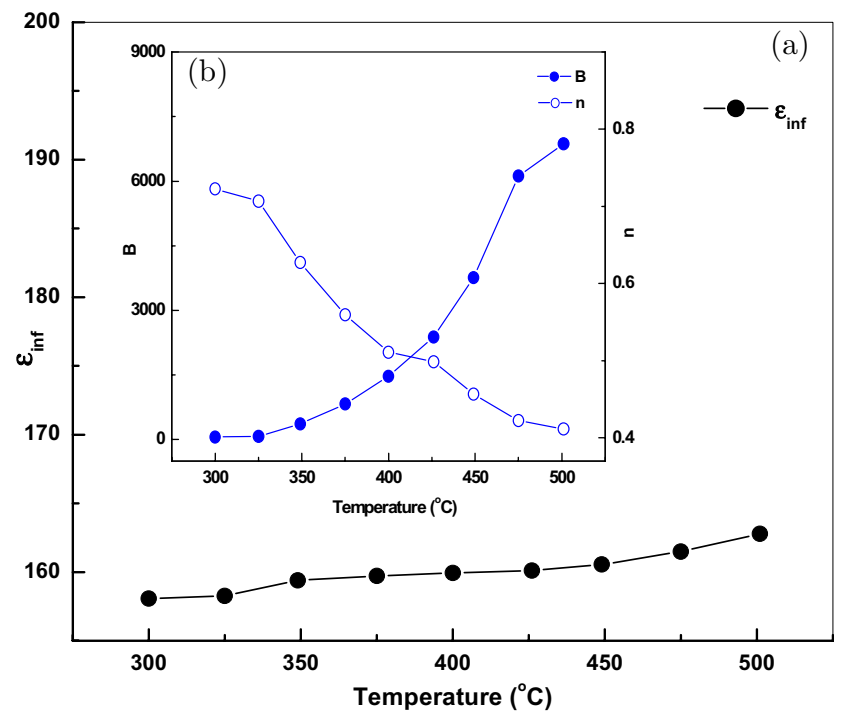

Fig. 3. Temperature dependence of dielectric fit parameters (a) $\varepsilon(\infty)$ and (b) $B$ and $n$.

using following equation: $\varepsilon(\omega)=\varepsilon_{\infty}+B \omega^{n-1}$, where $\varepsilon_{\infty}, B$ and $n$ are temperature-dependent parameters. ${ }^{37}$ The temperature dependence of fitting parameters is shown in Figs. 3(a) and 3(b). It is seen that the value of $\varepsilon_{\infty}$ increases slowly with temperature (Fig. 3(a)). Since $\varepsilon_{\infty}=\left(n_{r}\right)^{2}$, where $n_{r}$ is the refractive index, it can be expected that refractive index of the sample will attain a maximum value near transition temperature $\left(T_{c}\right)$. Figure $3(\mathrm{~b})$ shows the variation of other two parameters $B$ and $n$ with temperature. The pre-exponential factor $B$ indicates the strength of polarizability. The increase in value of $B$ with rise in temperature, suggests an increase in polarizability in the material on increasing the temperature. This observed value would attain a maximum around $T_{c}$ on account of maximum polarizability. ${ }^{38}$ The exponent $n$ represents interaction between mobile ions with the lattice around them. ${ }^{39}$ The plot reveals that the value of $n$ decreases with temperature. The decrease in the value of $n$ on increasing temperature suggests an increase in interaction between the lattices and mobile ions and can be explained on the basis of dynamical theory. ${ }^{37,39}$ As per this theory, one of the transverse optical modes (soft mode) gets weakened on increasing temperature and thereby, making the restoring force to decrease. As a result, the charge carriers, coupled with soft mode, become very mobile at this temperature and hence conductivity will also be increased. The temperature dependence plot of $n$ follows reversed trend than that followed by $B$. The nature of this temperature dependence of fitting parameters plots suggests the possible presence of ferroparaelectric $T_{c}$ towards still higher temperature side.

Figures 4(a) and 4(b) plots the dielectric loss $(\tan \delta)$ as a function of temperature and frequency. The plots reveal that the value of $\tan \delta$ is almost constant for a wide range of temperature and frequency. At $500^{\circ} \mathrm{C}, \tan \delta$ rather high at low frequency $(\sim 0.82$ at $10 \mathrm{kHz})$, but falls quickly with

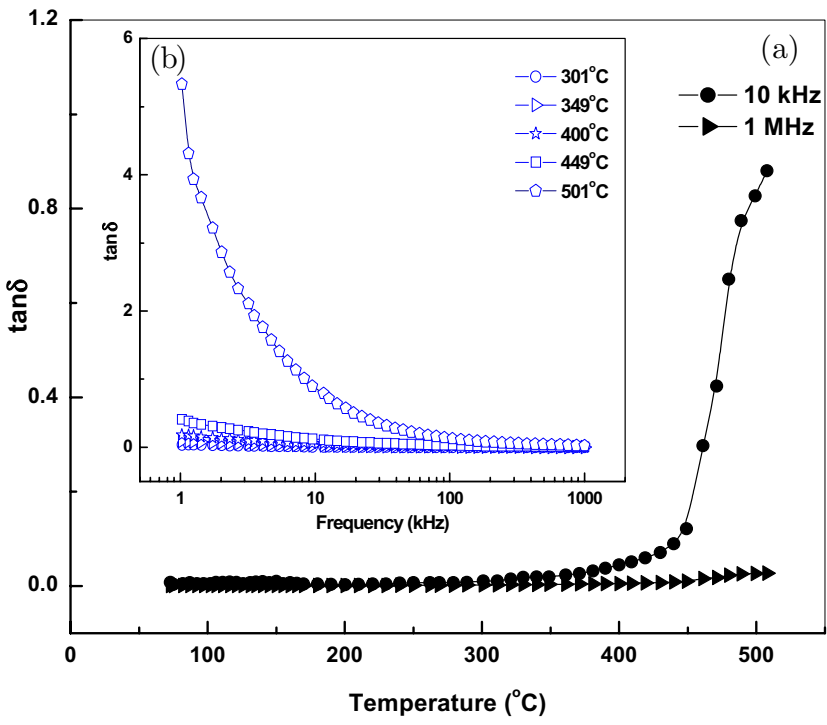

Fig. 4. (a) Temperature dependence of $\tan \delta$ of $\mathrm{Ba}_{3} \mathrm{~V}_{2} \mathrm{O}_{8}$ at various frequencies and (b) frequency dependence of $\tan \delta$ of $\mathrm{Ba}_{3} \mathrm{~V}_{2} \mathrm{O}_{8}$ at various temperatures.

increasing frequency $(\sim 0.026$ at $1 \mathrm{MHz})$. The nature of this temperature dependence of $\tan \delta$ and its values at various frequencies and temperature support our earlier study. Similar to the temperature dependence of $\varepsilon_{r}$, dielectric loss also increases on increasing temperature. This indicates the presence of thermally activated dielectric relaxation in the system. The sharp increase in $\tan \delta$ at low frequencies is an indication of the presence of dc conductivity in the sample. Again, the observed frequency dispersion in $\tan \delta$ at higher temperatures could be assigned to non-negligible ionic conductivity in the material arising out of oxygen-vacancy generated during sintering.

\subsection{Polarization study}

Figure 5 shows polarization versus electric field $(P-E)$ hysteresis loops of $\mathrm{Ba}_{3} \mathrm{~V}_{2} \mathrm{O}_{8}$ at three selected temperatures. The nature of $P-E$ loop at room temperature suggests the existence of ferroelectric properties in the material. The values of remanent polarization $\left(P_{r}\right)$ and coercive field $\left(E_{c}\right)$ were found to be $2.88 \mu \mathrm{C} / \mathrm{cm}^{2}$ and $3.072 \mathrm{kV} / \mathrm{cm}$ respectively at room temperature $\left(30^{\circ} \mathrm{C}\right)$. Further, there is a decrease in the values of respective parameters $\left(P_{r}, E_{c}\right)$ on increasing temperature, e.g., $\left(2.65 \mu \mathrm{C} / \mathrm{cm}^{2}, 2.793 \mathrm{kV} / \mathrm{cm}\right.$ at $\left.50^{\circ} \mathrm{C}\right)$ and $\left(2.057 \mu \mathrm{C} / \mathrm{cm}^{2}, 2.150 \mathrm{kV} / \mathrm{cm}\right.$ at $\left.100^{\circ} \mathrm{C}\right)$. The decrease in parameters $\left(P_{r}, E_{c}\right)$ and area of the loop, with temperature confirms the ferroelectric nature of the material. ${ }^{26,33}$

\subsection{Pyroelectric study}

The Pyroelectric current $(I)$, developed on the surface of the material sample, can be calculated using the relation: $I=\Gamma A \frac{d \theta}{d t}$ 


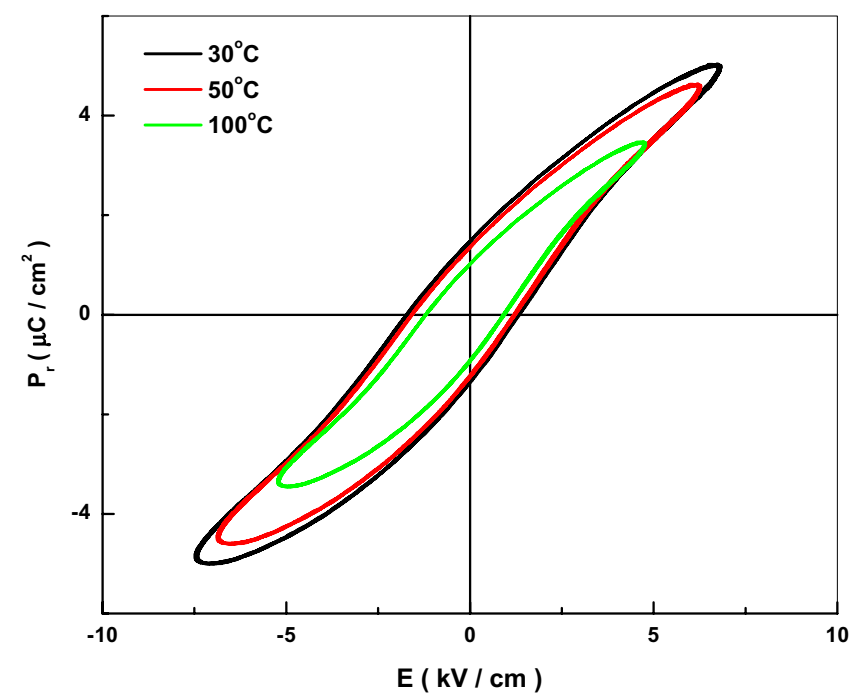

Fig. 5. Temperature dependence of hysteresis loop of $\mathrm{Ba}_{3} \mathrm{~V}_{2} \mathrm{O}_{8}$.

where $A$ is the area of the sample, $\Gamma$ is the pyroelectric coefficient and $\frac{d \theta}{d t}$ denotes the time rate of change of temperature of the material. ${ }^{40}$ Figures $6(\mathrm{a})$ and $6(\mathrm{~b})$ show the variation of pyroelectric current ( $\ln I$ ) and pyroelectric coefficient $[\Gamma]$ of $\mathrm{Ba}_{3} \mathrm{~V}_{2} \mathrm{O}_{8}$, as a function of temperature. The nature of temperature dependence plots support its dielectric study. ${ }^{41}$ The value of $\Gamma$ is found to be $9.31 \times 10^{2} \mu \mathrm{C} \cdot \mathrm{m}^{-2} \mathrm{C}^{\circ-1}$ at a temperature of $450^{\circ} \mathrm{C}$, which is quite high as compared to that of some earlier reported works on single crystals and/or ceramics such as $\mathrm{LiNbO}_{3}\left(83 \mu \mathrm{C} \cdot \mathrm{m}^{-2} \mathrm{C}^{\circ-1}\right), \mathrm{Pb}_{5} \mathrm{Ge}_{3} \mathrm{O}_{11}\left(110 \mu \mathrm{C} \cdot \mathrm{m}^{-2} \mathrm{C}^{\circ-1}\right)$, $\mathrm{Ba}_{3} \mathrm{Nb}_{2} \mathrm{O}_{8}\left(105 \mu \mathrm{C} \cdot \mathrm{m}^{-2} \mathrm{C}^{\circ-1}\right), \mathrm{PbTiO}_{3}\left(180 \mu \mathrm{C} \cdot \mathrm{m}^{-2} \mathrm{C}^{\circ-1}\right)$, SBN-50 $\left(550 \mu \mathrm{C} \cdot \mathrm{m}^{-2} \mathrm{C}^{\circ-1}\right)$, etc. ${ }^{39}$ The higher pyroelectric coefficient of the sample reflects its good stoichiometry. ${ }^{41}$

Pyroelectric figure of merits such as voltage responsivity $\left(F_{v}\right)$ and detectivity $\left(F_{d}\right)$ are important parameters to study the utility of the materials for their heat sensing

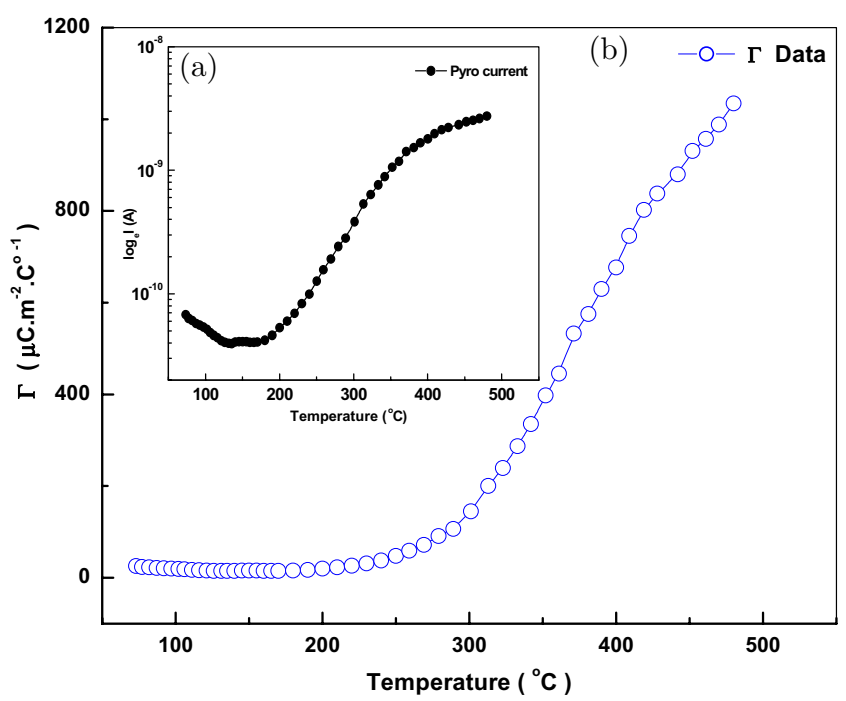

Fig. 6. Temperature dependence of pyroelectric current and pyroelectric coefficient of $\mathrm{Ba}_{3} \mathrm{~V}_{2} \mathrm{O}_{8}$.

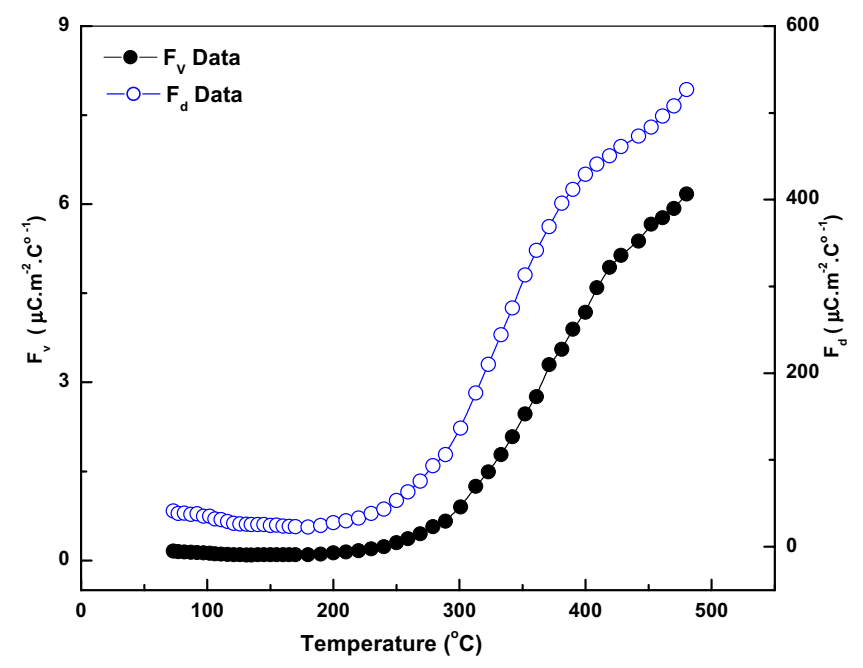

Fig. 7. Temperature dependence of figure of merits $\left(F_{V}\right.$ and $\left.F_{d}\right)$ of $\mathrm{Ba}_{3} \mathrm{~V}_{2} \mathrm{O}_{8}$.

applications. ${ }^{41}$ The voltage responsivity is generally calculated by using the empirical relation, ${ }^{42,43} F_{v}=\frac{\Gamma}{\varepsilon_{r}}$, where $\varepsilon_{r}$ is the relative permittivity of the material. However, for materials with relatively high dielectric loss, the detectivity plays the dominant role and is evaluated as per the relation, $F_{d}=\frac{\Gamma}{\sqrt{\varepsilon_{r} \tan \delta}}$. The figure of merits $\left(F_{v}\right.$ and $\left.F_{d}\right)$ are calculated from pyroelectric at $100 \mathrm{kHz}$ using the above empirical relations. The temperature dependence of $F_{v}$ and $F_{d}$ (Fig. 7) suggests that the material have relatively high voltage responsivity and detectivity as compared to some reported compounds. ${ }^{39}$ This may be attributed to space charge effect or enhanced activity of thermally agitated intrinsic charge carriers.

\subsection{J-E characteristics and dc conductivity analysis}

$J-E$ study on dielectric ceramics is one of the essential characterization tools to understand the conductivity mechanism in the sample. Figure 8(a) shows the variation of current density $(\ln J)$ with applied field $(E)$ for the material at some selected temperatures $200^{\circ} \mathrm{C}, 250^{\circ} \mathrm{C}, 300^{\circ} \mathrm{C}, 349^{\circ} \mathrm{C}$ and $400^{\circ} \mathrm{C}$, respectively. The plots reveal that the material allows a very small leakage current to pass through it. The increase in slope of characteristic curves with rise in temperature suggests an increase in conductivity of the material with temperature, and thus indicates its negative temperature coefficient of resistance (NTCR)-type behavior. The nature of $\ln J \sim E$ plot deviates from Ohmic nature and thus indicates the semiconducting nature of the material with a minute flow of leakage current.

Figure 8(b) shows the temperature dependence of dc electrical conductivity of the material (bulk), obtained from the slope of the linear portion of $J-E$ characteristics. The increase in $\sigma_{\mathrm{dc}}$ with temperature further supports the NTCR behavior of the sample. The nature of the plot follows the 


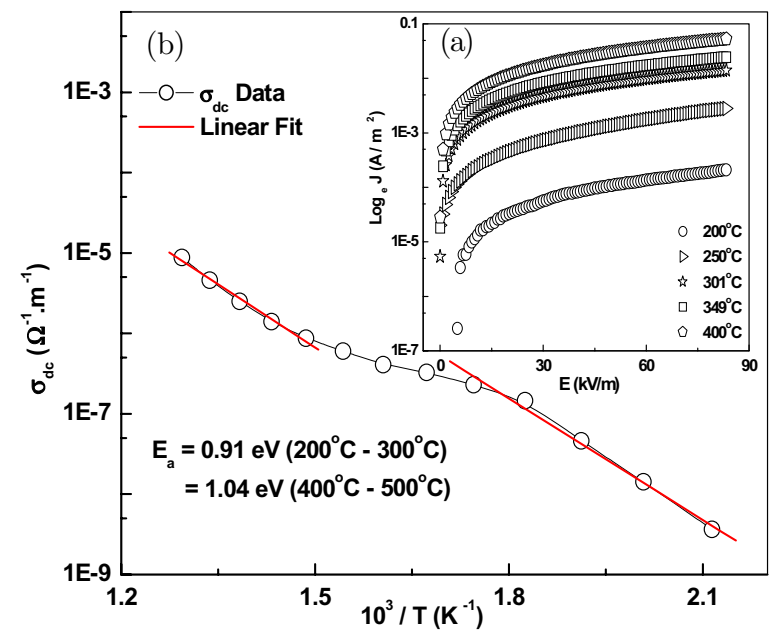

Fig. 8. Temperature dependence of (a) $J-E$ characteristics and (b) $\sigma_{\mathrm{dc}}$ of $\mathrm{Ba}_{3} \mathrm{~V}_{2} \mathrm{O}_{8}$.

Arrhenius relation: $\sigma_{\mathrm{dc}}=\sigma_{0} \exp \left(E_{a} / K_{B} T\right)$, where the symbols have their usual meanings. ${ }^{44}$ The occurences of different slopes at different temperature regions suggest the presence of multiple conduction processes in the sample with different activation energies. ${ }^{45,46}$ The calculated activation energy $\left(E_{a}\right)$ of the sample was found to be 0.91 and $1.04 \mathrm{eV}$ in medium $\left(200-300^{\circ} \mathrm{C}\right)$ and high $\left(400-500^{\circ} \mathrm{C}\right)$ temperature ranges. The occurrence of different activation energies also indicates that the conduction in the material occurs due to the hopping of charge carriers ${ }^{47}$ It is worth here to mention that in our earlier work on this compound, ${ }^{25}$ we have reported the temperature dependence of $\sigma_{\mathrm{dc}}$ (obtained from impedance studies). The nature of plots and the values of activation energy in different temperature ranges $(0.91 \mathrm{eV}$ in the temperature range: 200 $300^{\circ} \mathrm{C}$ ) agree well with those in the current work.

\section{Conclusion}

In summary, the present study reports the synthesis of a leadfree ceramic $\mathrm{Ba}_{3} \mathrm{~V}_{2} \mathrm{O}_{8}$ with a trigonal crystal structure at room temperature. The surface morphology shows homogeneously distributed grains. The dielectric study reveals that the material has moderate permittivity and very low loss even at high temperature. The moderate relative permittivity, low dielectric loss and high quality factor make this material (with suitable modifications) useful for microwave applications. The temperature dependence of hysteresis studies indicates the ferroelectric nature of the material. The pyroelectric study supports its dielectric response. The dc conductivity study reveals the NTCR behavior of the compound and the temperature dependence of $\sigma_{\mathrm{dc}}$ plot follows Arrhenius relation.

\section{Acknowledgments}

The authors would like to acknowledge the kind help of Dr. B. Mishra, Principal scientist, Dalmia Institute of Scientific and Industrial Research (DISIR), Rajgangpur, Odisha and IIT Kharagpur in performing some experimentation.

\section{References}

${ }^{1}$ J. Valsek, Piezo-electric and allied phenomena in Rochelle salt, Phys. Rev. 17(4), 475 (1921).

${ }^{2}$ B. Wull and J. M. Goldman, Ferroelectric switching in $\mathrm{BaTiO}_{3}$ ceramics, C. R. Acad. Sci. URSS 51, 21 (1946).

${ }^{3}$ H. D. Megaw, Origin of ferroelectricity in barium titanate other perovskite-type crystals, Acta Cryst. 5, 739 (1952).

${ }^{4}$ K. Uchino, Ferroelectric Devices (Marcel Dekker Inc, New York, 2000).

${ }^{5}$ M. E. Lines and A. M. Glass, Principle and Application of Ferroelectrics and Related Materials (Clarndon Press, Oxford, 1977).

${ }^{6}$ V. Bovtun, S. Veljko, S. Kamba, J. Petzelt, S. Vakhrushev, Y. Yakymenk, K. Brinkman and N. Setter, Broadband dielectric response of $\mathrm{PbMg}_{1 / 3} \mathrm{Nb}_{2 / 3} \mathrm{O}_{3}$ relaxor ferroelectrics: Single crystals, ceramics and thin films, J. Eur. Ceram. Soc. 26, 2867 (2006).

${ }^{7}$ Z. Y. Cheng, R. S. Katiyar, X. Yao and A. Guo, Dielectric behavior of lead magnesium niobate relaxors, Phys. Rev. B. 55, 8165 (1997).

${ }^{8}$ K. V. S. Raman, K. V. R. Murthy, K. Trinath and A. Bhanumati, Piezoelectric properties, hysteresis behavior and dielectric properties of PMN-PZT ceramics, Bull. Mater. Sci. 18, 587 (1995).

${ }^{9}$ G. H. Haertling, Ferroelectric ceramics: History and technology, J. Am. Ceram. Soc. 82, 797 (1999).

${ }^{10}$ H. Fan and H. E. Kim, Perovskite stabilization and electromechanical properties of polycrystalline lead zinc niobate-lead zirconate titanate, J. Appl. Phys. 91, 317 (2002).

${ }^{11}$ T. Takenaka, H. Nagata and Y. Hiruma, Current developments and prospective of lead-free piezoelectric ceramics, Jpn. J. Appl. Phys. 47, 3787 (2008).

${ }^{12}$ P. K. Panda, Review: Environmental friendly lead-free piezoelectric materials, J. Mater. Sci. 44(19), 5049 (2009).

${ }^{13}$ J. Rödel, W. Jo, K. T. P. Seifert, E. M. Anton, T. Granzow and D. Damjanovic, Perspective on the development of lead-free piezoceramics, J. Am. Ceram. Soc. 92(6), 1153 (2009).

${ }^{14}$ L. H. Brixner and P. L. Flournoy, Calcium orthovanadate $\mathrm{Ca}_{3}\left(\mathrm{VO}_{4}\right)_{2}$ - A new laser host crystal technical papers, J. Electrochem. Soc. 112, 303 (1965).

${ }^{15}$ P. Parhi, V. Manivanan, S. Kohli and P. McCurdy, Synthesis and characterization of $\mathrm{M}_{3} \mathrm{~V}_{2} \mathrm{O}_{8}(\mathrm{M}=\mathrm{Ca}, \mathrm{Sr}$ and $\mathrm{Ba})$ by a solid-state metathesis approach, Bull. Mater. Sci. 31(6), 885 (2008).

${ }^{16}$ E. G. Gonzalez, M. Parras and J. M. G. Calbet, Electron microscope study of a new cation deficient perovskite-like oxide: $\mathrm{Ba}_{3} \mathrm{MoNbO}_{8.5}$, Chem. Mater. 10, 1576 (1998).

${ }^{17}$ B. Mossner and S. K. Sack, 9R-Stapelvarianten vom Typ $\mathrm{Ba}_{3}(\mathrm{~B}$, $\left.\mathrm{B}^{\prime}\right)_{2} \mathrm{O}_{9-y}$ mit B, $\mathrm{B}^{\prime}=\mathrm{Mo}, \mathrm{W}, \mathrm{V}, \mathrm{Ti}$, J. Less Common Metals 114, 333 (1985).

${ }^{18}$ A. M. Glass, S. C. Abrahams, A. A. Ballmann and G. Laiacono, Calcium orthovanadate, $\mathrm{Ca}_{3}\left(\mathrm{VO}_{4}\right)_{2}-\mathrm{A}$ new high-temperature ferroelectric, Ferroelectrics 17, 579 (1977).

${ }^{19}$ A. Grzechnik, Crystal structure of $\mathrm{Ca}_{3}\left(\mathrm{VO}_{4}\right)_{2}$ synthesized at 11 GPa and 1373 K, Solid State Sci. 4, 523 (2002).

${ }^{20}$ R. Umemura, H. Ogawa, A. Yokoi, H. Ohsato and A. Kan, Lowtemperature sintering-microwave dielectric property relations in $\mathrm{Ba}_{3}\left(\mathrm{VO}_{4}\right)_{2}$ ceramic, J. Alloy Compd. 424, 388 (2006). 
${ }^{21}$ A. Grzechnik and P. F. McMillan, In situ high pressure raman spectra of $\mathrm{Ba}_{3}\left(\mathrm{VO}_{4}\right)_{2}$, Solid State Commun. 102, 569 (1997).

${ }^{22}$ L. D. Merkle, A. Pinto, H. Verdun and B. McIntosh, Laser action from $\mathrm{Mn}^{5+}$ in $\mathrm{Ba}_{3}\left(\mathrm{VO}_{4}\right)_{2}$, Appl. Phys. Lett. 61, 2386 (1992).

${ }^{23}$ B. Buijsse, J. Schmidt, I. Y. Chan and D. J. Singel, Electron spinecho-detected excitation spectroscopy of manganese doped $\mathrm{Ba}_{3}\left(\mathrm{VO}_{4}\right)_{2}$ : Identification of tetrahedral $\mathrm{Mn}^{5+}$ as the active laser center, Phys. Rev. B 51, 6215 (1995).

${ }^{24}$ P. Khatri, B. Behera and R. N. P. Choudhary, Structural and dielectric properties of $\mathrm{Ba}_{3} \mathrm{~V}_{2} \mathrm{O}_{8}$ ceramics, Curr. Appl. Phys. 9(2), 515 (2009).

${ }^{25}$ B. Pati, B. C. Sutar, B. N. Parida, P. R. Das and R. N. P. Choudhary, Dielectric and impedance spectroscopy of barium orthovanadate ceramics, J. Mater. Sci.: Mater. Electron. 24, 1608 (2013).

${ }^{26}$ B. Pati, R. N. P. Choudhary and P. R. Das, Phase transition and electrical properties of strontium orthovanadate, J. Alloys Compd. 579, 218 (2013).

${ }^{27}$ B. Pati, R. N. P. Choudhary, P. R. Das, B. N. Parida and R. Padhee, Dielectric and impedance spectroscopy of barium orthoniobate ceramics, J. Electron. Mater. 42, 1225 (2013).

${ }^{28} \mathrm{~K}$. B. Shim and C. S. Lim, MAS synthesis and characterization of $\mathrm{Sr}_{3} \mathrm{~V}_{2} \mathrm{O}_{8}$ nanoparticles, J. Ceram. Process. Res. 13, 291 (2012).

${ }^{29} \mathrm{E}$. Wu, POWD, an interactive powder diffraction data interpretation and indexing program, Ver. 2.1, School of Physical Sciences, Flinders University South Bedford Park, SA 5042, Australia.

${ }^{30}$ A. Durif, Structure crystalline des orthovanadates et orthoarseniates de barium et de strontium, Acta Cryst. 12, 420 (1959) (in French).

${ }^{31}$ J. C. Anderson, Dielectrics (Chapman \& Hall, London, 1964).

${ }^{32}$ L. E. Cross, Relaxor ferroelectrics, Ferroelectrics 76, 241 (1987).

${ }^{33}$ B. Pati, R. N. P. Choudhary and P. R. Das, Studies of dielectric, pyroelectric and conduction mechanism of $\mathrm{Sr}_{3} \mathrm{Ta}_{2} \mathrm{O}_{8}$, Ceram. Int. 40, 2201 (2014).

${ }^{34}$ T. A. Vanderah, T. R. Collins, W. Wong-Ng, R. S. Roth and L. Farber, Phase equilibria and crystal chemistry in the $\mathrm{Bao}-\mathrm{Al}_{2} \mathrm{O}_{3}$ $\mathrm{Nb}_{2} \mathrm{O}_{5}$ and Bao- $\mathrm{Nb}_{2} \mathrm{O}_{5}$ systems, J. Alloys Compd. 346, 116 (2002).
${ }^{35}$ C. G. Koops, On the dispersion of resistivity and dielectric constant of some semiconductors at audio frequencies, Phys. Rev. 83, 121 (1951).

${ }^{36}$ N. Singh, A. Agarwal, S. Sanghi and P. Singh, Synthesis, microstructure, dielectric and magnetic properties of $\mathrm{Cu}$ substituted Ni-Li ferrites, J. Magn. Magn. Mater. 323, 486 (2011).

${ }^{37}$ D. P. Almond and A. R. West, Impedance and modulus spectroscopy of "real" dispersive conductors, Solid State Ionic 11, 57 (1983).

${ }^{38}$ A. K. Jonscher, Dielectric Relaxation in Solids (Chelsea Dielectric Press, London, 1983).

${ }^{39}$ B. N. Parida, P. R. Das, R. Padhee and R. N. P. Choudhary, Phase transition and conduction mechanism of rare earth based tungstenbronze compounds, J. Alloys Compd. 540, 267 (2012).

${ }^{40} \mathrm{G}$. G. Roberts and B. Holcroft, Thermal imaging using organic films, Thin Solid Film 180, 211 (1989).

${ }^{41}$ P. Ganguli, S. Devi and A. K. Jha, Dielectric and pyroelectric studies of tungsten-bronze structured $\mathrm{Ba}_{5} \mathrm{SmTi}_{3} \mathrm{Nb}_{7} \mathrm{O}_{30}$ ferroelectric ceramics, Ferroelectrics 381, 111 (2009).

${ }^{42}$ R. Colbrook and G. G. Roberts, Pyroelectric Langmuir-Blodgett films incorporating metallic cations, Ferroelectrics 118, 199 (1991).

${ }^{43}$ M. Petty, J. Tsibouklis, F. Davis, P. Hodge, M. C. Petty and W. J. Feast, Pyroelectric Langmuir-Blodgett films prepared using preformed polymers, J. Phys. D: Appl. Phys. 25, 1032 (1992).

${ }^{44} \mathrm{~J}$. R. Macdonald, Note on parameterization of the constant phase admittance element, Solid state Ionics 13, 147 (1984).

${ }^{45}$ D. K. Pradhan, B. Behera and P. R. Das, Studies of dielectric and electrical properties of a new type of complex tungsten bronze electroceramics, J. Mater. Sci.: Mater. Electron. 23, 779 (2012).

${ }^{46}$ Z. Lu, J. P. Bonnet, J. Ravez and P. Hagenmuller, Correlation between low frequency dielectric dispersion (LFDD) and impedance relaxation in ferroelectric ceramic $\mathrm{Pb}_{2} \mathrm{KNb}_{4} \mathrm{TaO}_{15}$, Solid State Ionics 57, 235 (1992).

${ }^{47}$ D. K. Pradhan, R. N. P. Choudhary, C. Rinaldi and R. S. Katiyar, Effect of Mn substitution on electrical and magnetic properties of $\mathrm{Bi}_{0.9} \mathrm{La}_{0.1} \mathrm{O}_{3}$, J. Appl. Phys. 106, 24102 (2009). 